\title{
A Rare Case of Secondary Abdominal Pregnancy continuing up to Term with a Live Baby
}

\section{Bratati Moitra}

\section{ABSTRACT}

Secondary abdominal pregnancy is a very rare condition. Outcome of secondary abdominal pregnancy with pregnancy continuing up to term and delivering a live baby by laparotomy is more rare. Management of secondary abdominal pregnancy depends on the gestational age of the fetus when diagnosed. If not diagnosed at the correct time patient may have life-threatening complications, for example, massive intraperitoneal hemorrhage, peritonitis, intestinal obstruction, intestinal perforation, fecal fistula formation, and lithopedion formation.

Keywords: Abdominal, Hemorrhage, Pregnancy, Secondary.

How to cite this article: Moitra B. A Rare Case of Secondary Abdominal Pregnancy continuing up to Term with a Live Baby. J South Asian Feder Obst Gynae 2016;8(2):249-251.

\section{Source of support: Nil}

Conflict of interest: None

Date of received: 3 May 2016

Date of acceptance: 16 June 2016

Date of publication: July 2016

\section{INTRODUCTION}

Secondary abdominal pregnancy follows ruptured ectopic pregnancy or tubal abortion into peritoneal cavity. Typically growing placenta penetrates tubal wall, but placenta retains its attachment. Amniotic sac with fetus herniates out and continues to grow. Placenta encroaches and implants over neighboring structures. There is formation of a false sac for the growing fetus. Incidence of secondary abdominal pregnancy is 1 in 16,000 live births.

Stevens (1993) found that chance of survival of fetus beyond 30 weeks is $63 \%$. Fetal malformation and deformities were only $20 \%$.

\section{Assistant Professor}

Department of Obstetrics and Gynecology, Rajendra Institute of Medical Sciences, Ranchi, Jharkhand, India

Corresponding Author: Bratati Moitra, Assistant Professor Department of Obstetrics and Gynecology, Rajendra Institute of Medical Sciences, Ranchi, Jharkhand, India, Phone: +916512562377, e-mail: bgs2104@yahoo.co.in

\section{CASE REPORT}

A patient presented to the Rajendra Institute of Medical Sciences labor room on 19 December 2013 at 6:15 P.M.

The patient presented with term pregnancy with pain in the abdomen for 2 days. Patient was referred from the primary health center, Bero for fetal distress. She complained of abdominal pain from 4 months onward but did not consult any doctor. She took two doses of tetanus toxoid in Anganbari. No investigations were done.

Her menstrual history is as follows: Last menstrual period is March 25, 2013 and expected date of delivery is January 1, 2014. Obstetrical history - gravid -2, Para -1+0. Her first delivery was normal 2 years back in hospital. There was no history of any major medical or surgical illness.

\section{GENERAL EXAMINATION}

Patient was conscious and cooperative. Pallor + Pulse $86 /$ minute, blood pressure $-124 / 90 \mathrm{~mm} \mathrm{Hg}$, chest and cardiovascular - no abnormality detected, Per abdominal examination - uterus 30 weeks size, vague abdominal tenderness present. Lie longitudinal and presentation cephalic but fetus was felt superficial. Fetal heart rate 156/minute. Pelvic examination - cervix soft, anterior, very high up and behind pubic symphysis. External os patulous, internal os admits tip of finger. Fetal head appeared to be felt through postfornix.

An urgent ultrasonography (USG) of lower abdomen + pelvis was done. Few routine investigations were also done. Reports were as follows:

Blood group - B+

$\mathrm{Hb} \%-8 \mathrm{gm} / \mathrm{dL}$

T.C. $-17,000 / \mathrm{cmm}$

D.C. $-\mathrm{P}, 74 \%$; $\mathrm{L}, 13 \%$; $\mathrm{M}, 1 \%$; B, $7 \%$

Human immunodeficiency virus I and II: Negative HbsAg: Negative

USG showed bulky uterus which was well defined, smooth, and intact. No rupture was noted. Myometrium was homogenous and endometrium was central.

An extrauterine live fetus was noted superior to the uterus with 34 weeks gestational age. Placenta was situated above the fetus. Liquor was negligible.

Requisition for two units of blood was sent and patient was prepared for laparotomy. Two intravenous (IV) lines were secured with big-bore IV canula. Inj Xone $1 \mathrm{gm}$ 


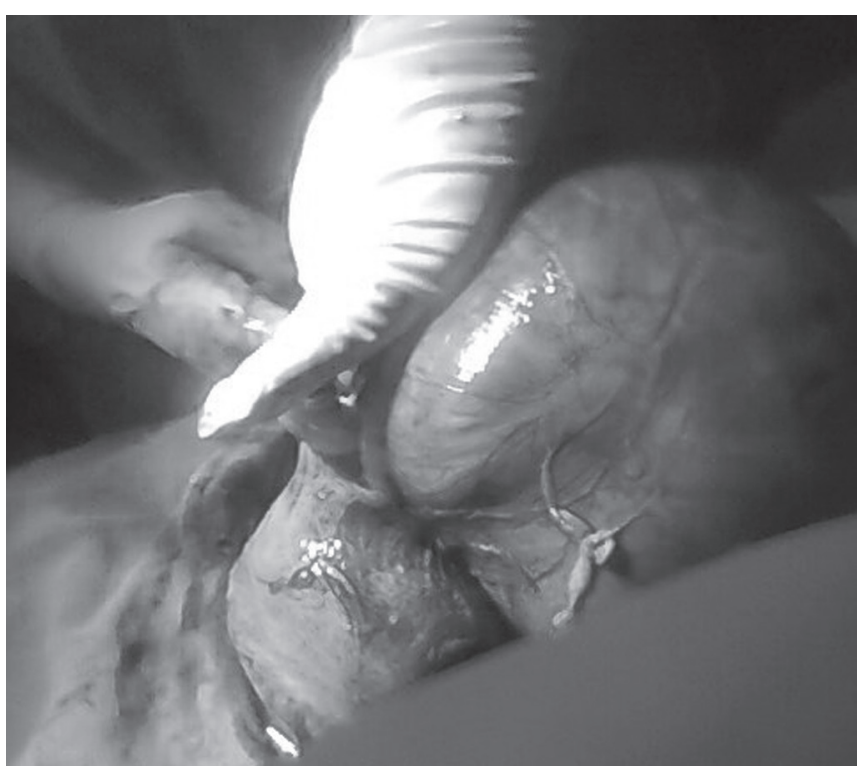

Fig. 1: Pseudo-sac with fetus and uterus is visible anteriorly

IV stat and then bd, metrogyl infusion 8 hourly, and gentamicin $80 \mathrm{mg}$ bd intramuscularly was started.

Under spinal anesthesia, abdomen was opened by midline incision, which was extended above the umbilicus. On opening peritoneal cavity, uterus was found on the left side of pelvis and of about 12 weeks size. There was no rent in the uterus (Fig. 1). There was a big gestational sac attached to the right broad ligament and extending downward behind the uterus. The sac was free from surrounding structure except on right side gut and appendix was adherent. Incision was given in upper part of sac and a live term male baby was delivered by breech at 11:05 A.M. on December 20, 2013 (Fig. 2). Head was in pouch of Douglas. Baby was smeared with meconium and liquor was negligible. Placenta was implanted over omentum, which was removed after clamping and cutting after transfixation of big vessels along with a portion of omentum. Appendicectomy was done as it was adherent with sac. A portion of sac could not be removed as it was adherent to pelvic colon. Intraperitoneal drain was given. Abdomen was closed after hemostasis was secured and after counting instruments and tetras.

Baby cried after resuscitation and was sent to the neonatal intensive care unit (Fig. 3). Postoperative period was uneventful, except for distension of abdomen for 48 hours. Drain was removed on 3rd day. Stitches were removed on 8 th day and patient was discharged on 9th day.

\section{DISCUSSION}

An abdominal pregnancy is a life-threatening condition and clinical management depends on gestational age at the time of diagnosis. ${ }^{1}$ Some practitioners wait for fetal

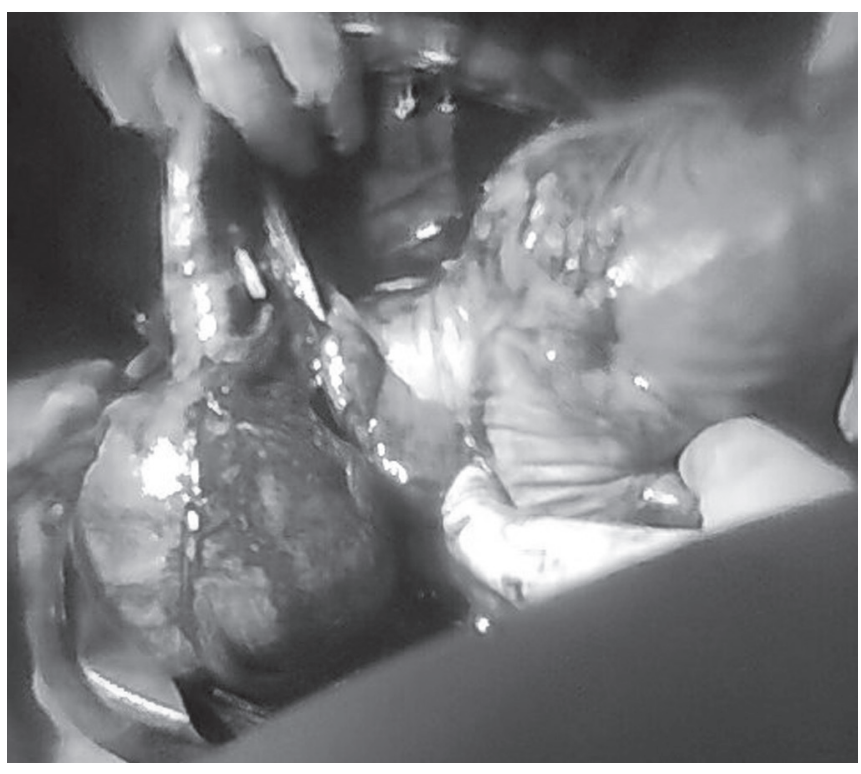

Fig. 2: Fetus being delivered from pseudo-sac

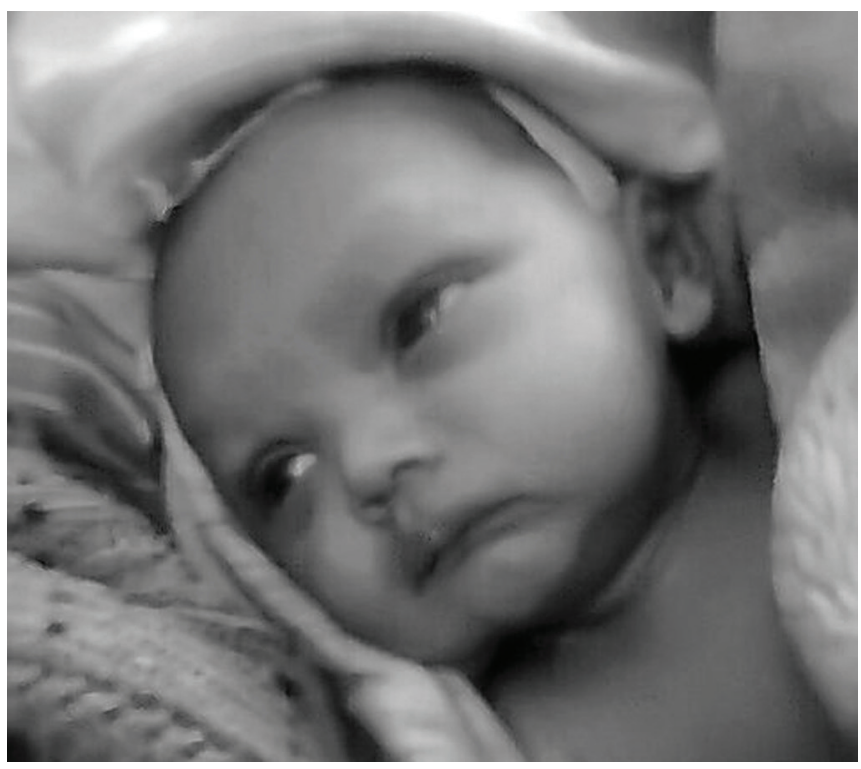

Fig. 3: A live baby delivered by laparotomy

maturity provided fetus is alive and patients are admitted with daily monitoring with expectant management. ${ }^{2}$ Such management carries risk of sudden intraperitoneal hemorrhage. Conservative approach is not justified if gestational age is $<24$ weeks with negligible liquor. Chance of fetal survival is extremely poor.

During laparotomy, if placenta is adherent and implanted over vital organ, it can be left as such but it increases chance of infection, abscess formation, adhesion, intestinal obstruction, etc. ${ }^{3}$ If placenta is left behind, its involution should be monitored by ultrasound, color Doppler, and $\beta$-human chorionic gonadotropin level. ${ }^{4,5}$ Arterial catheterization and embolization is life saving in some cases if there is massive intraperitoneal hemorrhage. ${ }^{6}$ 


\section{REFERENCES}

1. Cartwright PS, Brown JE, Davis RJ, Thieme GA, Boehm FH. Advanced abdominal pregnancy associated with fetal pulmonary hypoplasia: report of a case. Am J Obstet Gynecol 1986 Aug;155(2):396-397.

2. Hage ML, Wall LL, Killam A. Expectant management of abdominal pregnancy. A report of two cases. J Reprod Med 1988 Apr;33(4):407-410.

3. Bergstrom R, Mueller G, Yankowitz J. A case illustrating with continued dilemmas in treating abdominal pregnancy and a potential explanation for high rate of postsurgical female morbidity. Gynecol Obstet Invest 1998;46(4):268-270.
4. Martin JN Jr, Sessums JK, Martin RW, Pryor JA, Morrison JC. Abdominal pregnancy current concepts of management. Obstetric \& Gynaecology 1998;71(4):549-557 PMID 3281075

5. France JT, Jackson P. Maternal plasma and urinary hormone level during and after successful abdominal pregnancy. Br J Obstet Gynaecol 1980 May;87(5):356-362.

6. Martin JN Jr, MC caul JF IV. Emergent management of abdominal pregnancy clinical obstet \& Gynecol 1996;33: 438.

7. Stevens CA. Malformation \& deformation in abdominal pregnancy. Am J Med Genet 1993;47(8):1189-1193. 
